\title{
Техника электрохимического вольт-фарадного профилирования сильно легированных структур с резким профилем распределения примеси
}

\author{
(С) Д.С. Фролов, Г.Е. Яковлев, В.И. Зубков \\ Санкт-Петербургский государственный электротехнический университет „ЛЭТИ“ им. В.И. Ульянова (Ленина), \\ 197376 Санкт-Петербург, Россия \\ E-mail: frolovds@gmail.com
}

(Получена 1 августа 2018 г. Принята к печати 13 августа 2018 г.)

Рассмотрены особенности применения метода электрохимического вольт-фарадного профилирования для исследования сильно легированных структур с резким профилем распределения примеси. Приведены критерии и даны рекомендации выбора оптимальных параметров измерения, обоснована необходимость увеличения частоты, при которой измеряется емкость в процессе профилирования. Описанная методика рассмотрена на примере профилирования кремниевых структур $p$-типа с ионной имплантацией, а также $n$-GaAs эпитаксиальных и подложечных структур для $p$ НЕМТ приборов.

DOI: $10.21883 / F T P .2019 .02 .47114 .8966$

\section{1. Введение}

Разработка и создание новых материалов и структур для полупроводниковой электроники требуют соответствующего развития средств диагностики их параметров. Среди электрических методов диагностики полупроводников метод электрохимического вольт-фарадного (ECV) профилирования выделяется тем, что не требует специальной подготовки структур и нанесения контактов для проведения измерений, позволяя получать информацию не только о распределении примеси, но и о распределении свободных носителей заряда.

Метод ECV был впервые представлен в 1974 г. [1] и долгое время его применение было ограничено только бинарными полупроводниками $\mathrm{A}^{\mathrm{III}} \mathrm{B}^{\mathrm{V}}$ (в основном $\mathrm{GaAs})$ из-за сложностей в выборе подходящего электролита и режимов травления других материалов [2,3]. В последнее время интерес к использованию ECV-профилирования значительно вырос в связи с ростом актуальности солнечных элементов и других приборов фотоэлектроники и фотоники на основе $\mathrm{Si}$, а также необходимости отработки новых технологических процессов для повышения их эффективности и удешевления производства [4-6]. Для таких структур характерно использование резкого профиля легирования примеси за счет чередования тонких гетерослоев, либо имплантация высокой дозы примеси [7]. В работах авторов [8,9] было предложено использование состава $\mathrm{NH}_{3} \mathrm{HF}_{2}$ для электрохимического травления кремния, а также даны рекомендации по выбору параметров процесса травления. Однако приведенные рецепты в цитированных и других публикациях обеспечивают достоверные результаты, как правило, только для однородно легированных структур или когда имеет место плавно изменяющаяся по глубине образца концентрация примеси.

В методе электрохимического вольт-фарадного профилирования традиционно измерения проводятся при фиксированной частоте, которая выбирается в начале из- мерений. Такой подход также корректен для простых однородно легированных структур, однако, как показывает экспериментальный опыт, в случае резкого снижения концентрации примеси в глубину образца такая техника может вызывать появление различных артефактов на измеряемом концентрационном профиле [10,11].

Цель данной работы - исследование полупроводниковых структур с резко неоднородным профилем концентрации примеси методом электрохимического вольтфарадного профилирования и выработка критериев выбора оптимальных параметров для проведения электрохимического травления и емкостных измерений подобных структур. В качестве объектов измерения использовались кремниевые структуры, подвергнутые ионной имплантации, и образцы легированного эпитаксиального $n$-GaAs.

\section{2. Образцы и техника эксперимента}

В работе исследовались ионно-имплантированные кремниевые структуры, используемые при производстве приборов фотоэлектроники с обратной засветкой. Ионная имплантация в структуры проводилась бором с энергией 20 кэВ с последующим низкотемпературным $\left(450^{\circ} \mathrm{C}\right)$ отжигом. Более подробное описание структур дано в предыдущей работе [12]. В качестве образцов сравнения проводились измерения эпитаксиальных структур GaAs, используемых при производстве $p \mathrm{HEMT}$ приборов [13]. Структуры представляли собой слои $n$-типа с уровнем легирования $2 \cdot 10^{17} \mathrm{~cm}^{-3}$, выращенные молекулярно-пучковой эпитаксией на полуизолирующей подложке арсенида галлия.

Измерение профилей концентрации проводилось на установке электрохимического вольт-фарадного профилирования ECVPro (Nanometrics). При исследовании кремниевых структур в качестве электролита нами использовался водный раствор бифторида аммония 
$\left(\mathrm{NH}_{4} \mathrm{HF}_{2}\right)$ в концентрации $0.1-0.2 \mathrm{M}$ с добавлением изопропилового спирта в размере $20 \%$ от объема раствоpa. Для структур GaAs использовался электролит Tiron $\left(\mathrm{C}_{6} \mathrm{H}_{4} \mathrm{Na}_{2} \mathrm{O}_{8} \mathrm{~S}_{2}\right)$ с концентрацией $0.1 \mathrm{M}$.

\section{3. Экспериментальные результаты и обсуждение}

В процессе измерений ионно-имплантированных кремниевых структур $p$-типа в штатном режиме профилометра нами были зарегистрированы артефакты, выражающиеся в аномальном увеличении наблюдаемой концентрации. В данном разделе анализируются причины их появления и методы устранения. Для структур с резким снижением концентрации примеси в глубь образца теоретически обосновывается и экспериментально демонстрируется необходимость перманентного увеличения частоты тестового сигнала для обеспечения корректных измерений емкости и концентрации по мере профилирования.

\section{1. Выбор оптимальных параметров для измерения концентрации в структурах с резких профилем распределения примеси}

Электрохимическое вольт-фарадное профилирование состоит из двух принципиально различающихся процессов: электрохимического травления материала и измерения вольт-фарадных характеристик. В данном подразделе развивается алгоритм выбора оптимальных значений напряжения смещения и частоты измерения при проведении ECV-измерений структур с резким профилем распределения примеси.

В структурах с высоким содержанием примеси в приповерхностной области и резким падением концентрации в объеме выбор напряжения смещения затруднен тем, что диапазон напряжений, в котором можно проводить измерения, достаточно узкий, а резкое изменение концентрации приводит к нелинейности вольтфарадной характеристики в координатах Мотта-Шоттки $\left(1 / c^{2}\right.$ vs. $\left.U\right)$. В этом случае при выборе оптимального напряжения смещения следует ориентироваться на минимизацию тангенса угла диэлектрических потерь $\operatorname{tg} \delta$; при этом выбранное напряжение остается неизменным на всем протяжении профилирования, если по мере травления слоев не меняется материал или тип проводимости. При исследовании кремниевых структур, имплантированных ионами бора, нами выбиралось напряжение смещения (рабочая точка) -1 В относительно платинового электрода электрохимической ячейки установки.

Иная ситуация имеет место при выборе частоты измерения. При использовании фиксированной частоты для измерения емкости в таких структурах становится невозможно корректное измерение профиля на большую глубину (рис. 1, кривая 1). Это связано с тем, что по мере травления структуры и уменьшения концентрации

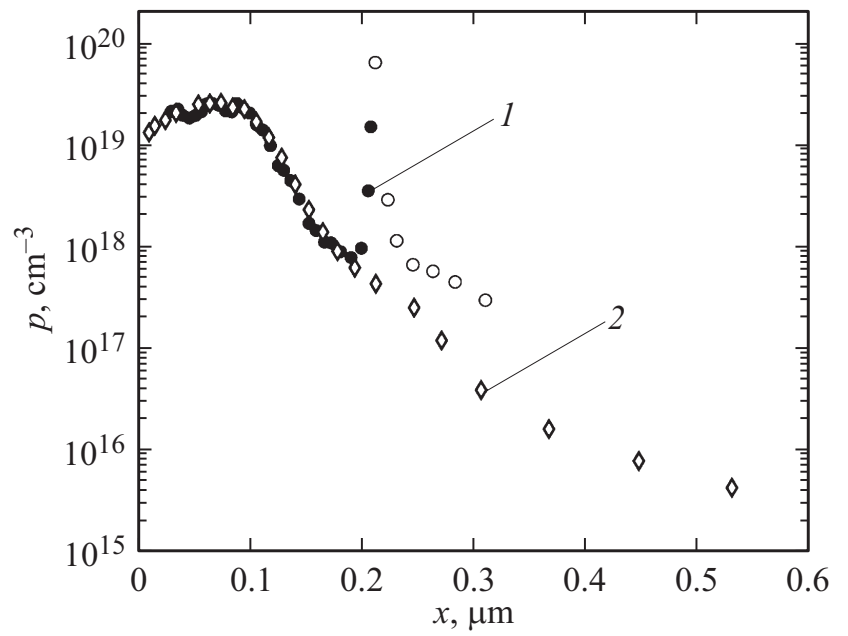

Рис. 1. Пример артефакта, связанного с выбором частоты измерений при исследовании ионно-имплантированных кремниевых структур: 1 - измерения на фиксированной частоте (незакрашенными символами показано изменение знака измеряемой концентрации), 2 - измерения с увеличением частоты по мере травления.

носителей заряда падает барьерная емкость перехода электролит-полупроводник. Кроме того, большая концентрация примеси в приповерхностной области вызывает рост паразитной проводимости и соответственно активных потерь. Оптимальным рецептом и в таком случае является стремление к минимизации тангенса угла потерь. Это требование приводит к необходимости перманентно увеличивать частоту, на которой производится измерение емкости, в ответ на увеличение отношения активной к реактивной составляющих комплексного адмиттанса.

Рассмотрим эту проблему на примере трехкомпонентной эквивалентной схемы измерений, представленной на рис. 2. Запишем полное сопротивление такой схемы:

$$
\begin{aligned}
Z & =R-j X \\
& =\frac{R_{s}\left(1+\omega^{2} C^{2} R_{p}^{2}\right)+R_{p}}{1+\omega^{2} C^{2} R_{p}^{2}}-j \frac{\omega C^{2} R_{p}^{2}}{1+\omega^{2} C^{2} R_{p}^{2}},
\end{aligned}
$$

где $\omega-$ частота измерений емкости, $C-$ барьерная емкость перехода на конкретной глубине травления. При этом $R_{s}$ и $R_{p}$ - паразитные элементы используемой эквивалентной схемы, которые также могут меняться в процессе профилирования.

Отношение вещественной и мнимой составляющей адмиттанса в такой схеме будет равно:

$$
\operatorname{tg} \delta=\frac{R}{X}=\omega C R_{s}+\frac{1+R_{s} / R_{p}}{\omega C R_{p}} .
$$

Продифференцировав выражение (2) по частоте, найдем значение частоты, при которой $\operatorname{tg} \delta$ минимален:

$$
f_{\text {opt }}=\frac{1}{2 \pi} \sqrt{\frac{1+R_{s} / R_{p}}{C^{2} R_{s} R_{p}}} .
$$


Учитывая, что $R_{s}$ и $R_{p}$ за время измерения изменяются в несколько раз, тогда как емкость уменьшается на 2 порядка, мы можем упростить анализ, приняв $R_{s}$ и $R_{p}$ постоянными. В таком случае на выбор оптимальной частоты будет влиять только изменение барьерной емкости. На рис. 2 приведены графики изменения емкости и частоты, при которой производились вольт-фарадные измерения, в процессе профилирования ионно-имплантированной структуры. За величиной $x_{r}+x_{d}$ скрывается сумма глубины травления и ширины области объемного заряда. Оптимальная частота измерений была построена по выражению (3) с использованием фиксированных параметров для $R_{s}$ и $R_{p}$, равных 750 Ом и 200 кОм. Изменение частоты в данном эксперименте было дискретным из-за ограничения по выбору частот, имеющегося в установке ECVPro.

Сравнение профилей распределения концентрации, измеренных при фиксированной частоте и с использованием оптимальных частот, приведено на рис. 1. При использовании фиксированной частоты на глубине $\sim 0.2$ мкм наблюдается резкий рост концентрации с последующим изменением типа проводимости. Такой эффект вызван изменением знака тангенса угла наклона вольт-фарадной характеристики из-за влияния последовательного сопротивления и паразитной проводимости [14].

При изменении частоты измерения емкости в соответствии с предлагаемой методикой для данной структуры, как видно, удается измерить профиль в диапазоне концентраций от $10^{15}$ до $10^{19} \mathrm{~cm}^{-3}$.

Для проверки корректности предложенной методики выбора оптимальной частоты в процессе ECV-профилирования было проведено сравнение результатов из-

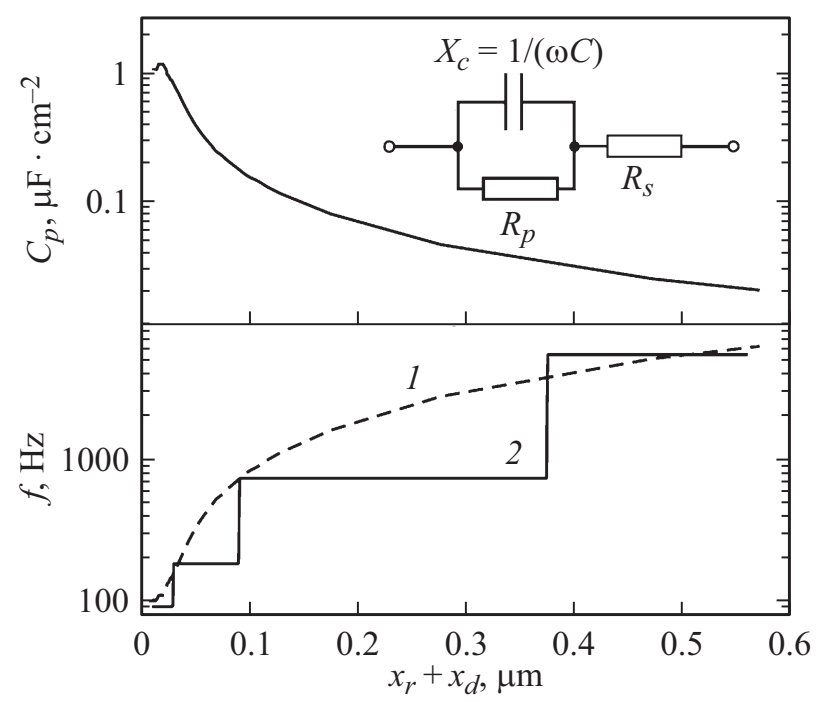

Pис. 2. Изменение емкости и задаваемой частоты тестового сигнала по мере травления ионно-имплантированного бором образца Si. На вставке: эквивалентная схема, использованная для расчета: 1 - оптимальная частота, 2 - частота, используемая в эксперименте.

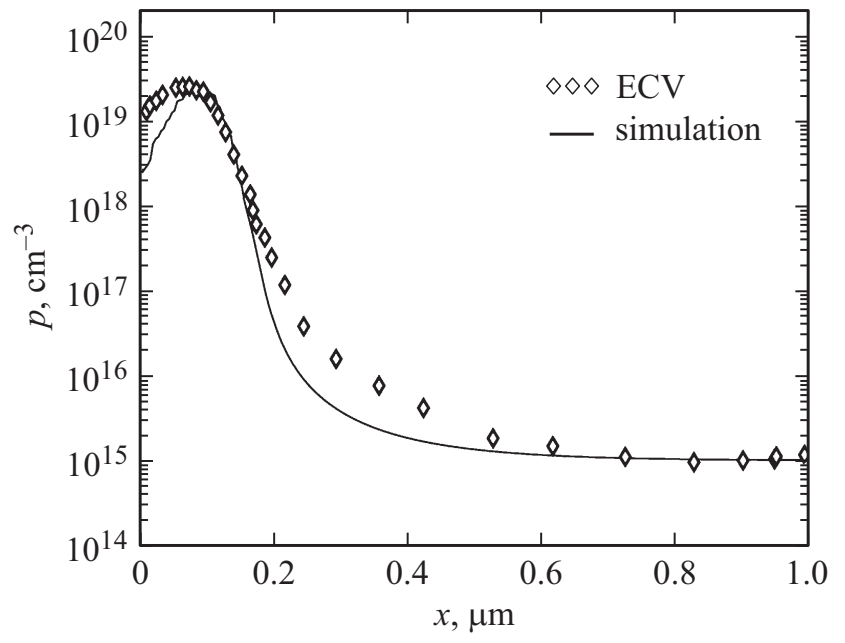

Рис. 3. Сравнение ECV-профиля и рассчитанного профиля распределения свободных носителей заряда в $p$-Si-cтруктуре с ионной имплантацией бором с энергией 20 кэВ.

мерений с результатами расчета распределения концентрации примеси, выполненного с помощью численного решения нелинейного уравнения Пуассона.

На рис. 3 приведены результаты измерений методом $\mathrm{ECV}$ (точки) и расчета (сплошная линия) для кремния КДБ-12, имплантированного ионами бора с энергией 20 кэВ. Моделирование профиля имплантации проводилось в программе SRIM (The Stopping and Range of Ions in Matter) [15]. В приповерхностной области наблюдается хорошее совпадение пика распределения концентрации примеси и профиля концентрации основных носителей заряда (ОН3). Различие в ширине профиля частично связано с ограничениями программы SRIM [12], не учитывающей взаимодействие заряженных ионов между собой при расчете распределения примеси, что характерно для малых энергий имплантации, а также с использованным в работе нестандартным низкотемпературным отжигом $[16,17]$.

Помимо ионно-имплантированных полупроводников, резкий градиент распределения примеси имеет место, например, в эпитаксиальных НЕМТ структурах, выращенных на полуизолирующих подложках. Применение предлагаемой методики выбора и подстройки оптимальной частоты в процессе измерения концентрации обеспечивает получение корректных результатов, что делает ECV-профилирование весьма эффективным диагностическим методом при отработке технологических процессов изготовления подобных структур [13]. На рис. 4 приведен ECV-профиль концентрации в $p$ HЕМТ-структуре с сильно легированным эпитаксиальным слоем GaAs, выращенным на полуизолирующей гомоподложке. Здесь же для сравнения приведены результаты проведенного расчета профиля распределения электронов, при этом глубина кратера и толщины слоев контролировались методом АСМ и оптическими интерференционными методами. Как видно, техника ECV-профилирования с под- 


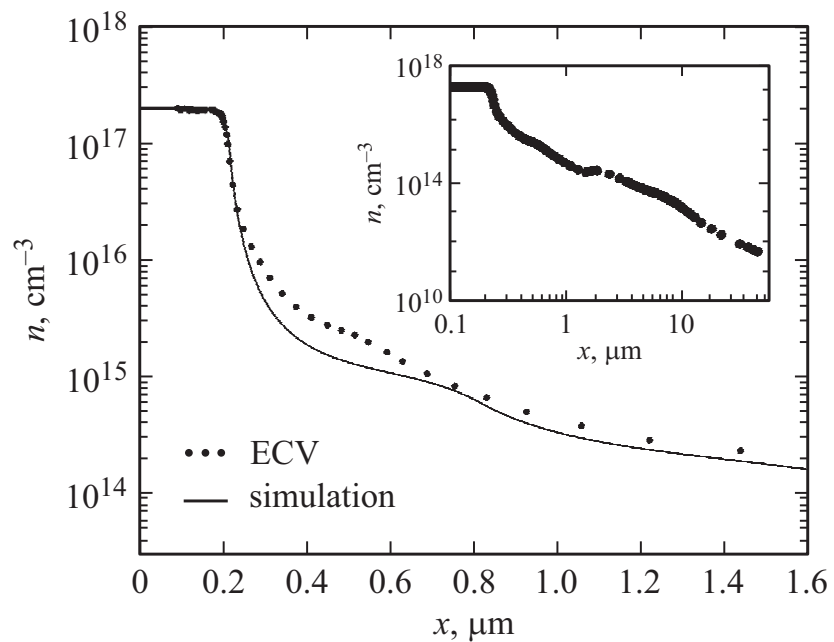

Рис. 4. Сравнение ECV-профиля и рассчитанного профиля распределения свободных носителей заряда в легированном эпитаксиальном слое GaAs на полуизолирующей подложке. На вставке приведен тот же профиль в другом масштабе.

стройкой частоты обеспечивает аккуратные измерения неоднородно легированных образцов с проникновением в диапазон глубин порядка десятков микрометров, при этом имеет место хорошее соответствие с ожидаемыми расчетными данными и результатами измерений концентрации методом Холла.

Рассмотренная выше структура интересна, в том числе, и с точки зрения измерения концентрации примеси в слабо легированных подложках $\mathrm{GaAs}$, к которым создание металлических омических контактов напрямую затруднено. Использование тестовых структур с легированными слоями на поверхности полуизолирующей подложки позволяет при помощи метода электрохимического вольт-фарадного профилирования проводить измерение профиля концентрации в области подложки. Расширение диапазона профилирования в таких структурах за счет использования оптимальных частот позволяет проводить измерения концентрации вплоть до $10^{11} \mathrm{~cm}^{-3}$.

\section{2. Причины неравномерного электрохимического травления в структурах с резким градиентом примеси}

При электрохимическом вольт-фарадном профилировании полупроводниковых структур на большую глубину для сокращения времени измерений отдельного образца существует соблазн увеличения тока травления или интенсивности подсветки электролитического контакта (при профилировании структур $n$-типа проводимости). Однако чрезмерное увеличение тока травления приводит к появлению на наблюдаемом концентрационном профиле артефактов, связанных с наличием неоднородного травления стенок кратера. Так, при ECV-профилировании структур $p$-типа с резким профилем распределения примеси в экспериментах имели место артефакты, связанные с ростом измеряемой концентрации при большой глубине травления (рис. 5).

Неоднородное травление в таких структурах возникает из-за того, что при изменении концентрации примеси в полупроводнике меняется соотношение падений напряжения между слоем Гельмгольца и областью объемного заряда (ОО3) в полупроводнике. В рассматриваемой структуре при одинаковом потенциале $p^{+}$-область будет травиться быстрее (ток травления больше) нежели $p$-область, что и приводит к неоднородному травлению слоев. Это в свою очередь даст завышенное значение наблюдаемой концентрации в глубине структуры из-за того, что к емкости барьерного слоя на дне кратера

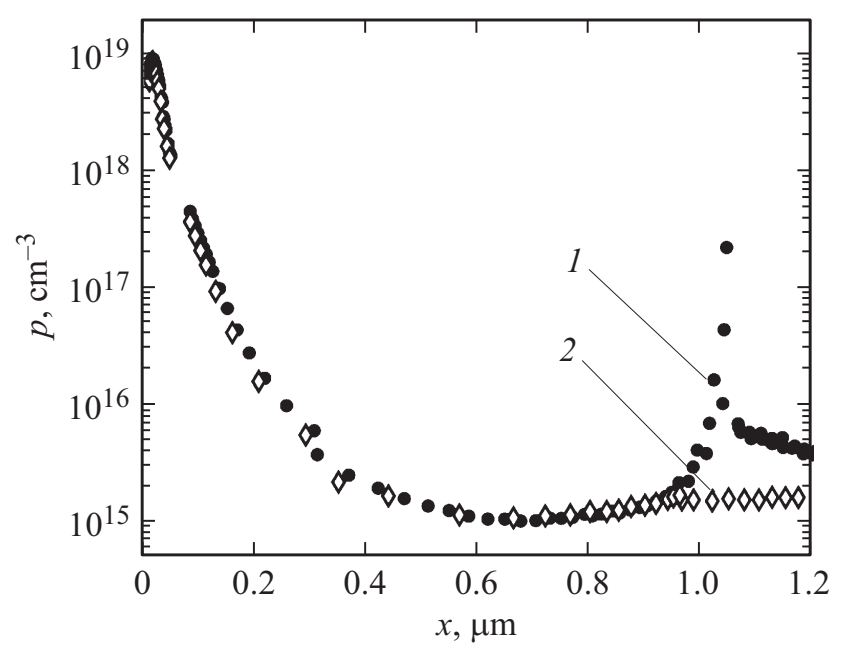

Рис. 5. Пример артефакта в наблюдаемом ECV-профиле распределения концентрации, возникающего при неоднородном травлении $p^{+}-p$-структур.

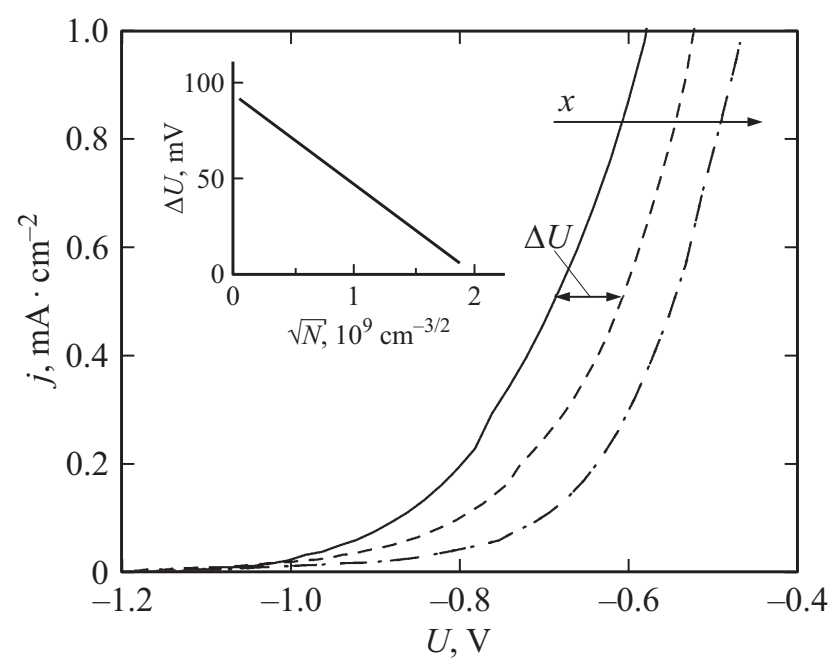

Рис. 6. Типичные BAX, измеренные в процессе ECV-профилирования на разной глубине травления $\mathrm{Si}$. На вставке зависимость изменения анодного потенциала от концентрации акцепторов. 
добавляется емкость перетравленного сильно легированного слоя вблизи поверхности. Выбор режима травления (рис. 6) влияет на то, как сильно проявляется этот эффект. Нами показано, что уменьшение тока травления до уровня $0.2 \mathrm{MA} / \mathrm{cm}^{2}$ значительно снижает выбросы на измеряемом концентрационном профиле, связанные с неоднородным травлением кремния.

Заметим, что, поскольку смещение анодного потенциала $\Delta U$ в электрохимической ячейке пропорционально корню из концентрации, данный факт может быть использован для построения графика распределения концентрации альтернативным методом, использованным в работе [18]. Так, для полупроводника $p$-типа:

$$
\Delta U=\frac{1}{C_{\mathrm{H}}} \sqrt{2 q \varepsilon_{s}\left(\Delta \varphi_{s c}-\frac{k T}{q}\right)} \sqrt{N_{A}},
$$

где $C_{\mathrm{H}}$ - емкость слоя Гельмгольца, $\Delta \varphi_{s c}$ - высота барьера на границе раздела полупроводник/электролит, $N_{A}$ - концентрация акцепторов в полупроводнике.

В отличие от метода электрохимического вольтфарадного профилирования, для определения абсолютного значения концентрации в отмеченной методике необходимо проводить дополнительную калибровку для определения соответствия между уровнем легирования и величиной $\Delta U$. В дополнение к этому, величина изменения потенциала электрода сильно меняется в зависимости от качества подготовки поверхности и выбора параметров травления, что также может привести к существенной ошибке при определении концентрации.

\section{4. Заключение}

В настоящей работе проведено исследование методом электрохимического вольт-фарадного профилирования кремниевых структур, подвергнутых ионной имплантации, и эпитаксиальных GaAs $p$ HEMT структур на полуизолирующей подложке. Показано, что электрохимическое травление $p^{+}-p$-структур при постоянном напряжении смещения может приводить к неравномерному травлению из-за того, что скорость травления $p^{+}$-слоя значительно выше, чем скорость травления слабо легированного слоя. Это в свою очередь ведет к резкому росту концентрации на наблюдаемом ECV-профиле распределения ОНЗ. Для устранения данного артефакта следует выбирать оптимальное напряжение смещения, ориентируясь на минимизацию тангенса угла диэлектрических потерь.

При проведении ECV-профилирования структур с резким уменьшением концентрации примеси в глубь структуры необходимо увеличивать частоту измерений по мере травления, для того чтобы компенсировать падение барьерной емкости, сопровождаемое ростом тангенса угла диэлектрических потерь. Использование предложенной методики выбора оптимальных частот для электрохимического вольт-фарадного профилирования подложечных $\mathrm{GaAs}$ структур позволяет проводить измерения чрезвычайно малых концентраций примеси глубоко в подложке, вплоть до $10^{11} \mathrm{~cm}^{-3}$.

\section{Список литературы}

[1] T. Ambridge, M.M. Faktor. Electron. Lett., 10 (10), 204 (1974).

[2] C.D. Sharpe, P. Lilley, C.R. Elliott, T. Ambridge. Electron. Lett., 15 (20), 622 (1979).

[3] M. Pawlik, R.D. Groves, R.A. Kubiak, W.Y. Leong, E.H.C. Parcker. Emerg. Semicond. Technol. ASTM STP 960 [ed. by D.C. Gupta, P.H. Larger, 558 (1987)].

[4] F. Kiefer, J. Krügener, F. Heinemeyer, H.J. Osten, R. Brendel, R. Peibst. IEEE J. Photovolt., 6 (5), 1175 (2016).

[5] P. Rothhardt, S. Meier, R. Hoenig, A. Wolf, D. Biro. Solar Energy Mater. and Solar Cells, 153, 25 (2016).

[6] B. Sermage, Z. Essa, N. Taleb, M. Quillec, J. Aubin, J.M. Hartmann, M. Veillerot. J. Appl. Phys., 119 (15), 155703 (2016).

[7] Д.Е. Миронов, М.Р. Айнбунд, В.И. Зубков. Тр. XXV Мехсдунар. науч.-техн. конф. по фботоэлектронике $и$ приборам ночного видения (М., Россия, 2018) т. 1, с. 129.

[8] N. Sieber, H.E. Wulf, D. Röser, P. Kurps. Phys. Status Solidi, A, 126 (2), K123 (1991).

[9] E. Peiner, A. Schlachetzki. J. Electrochem. Soc., 139 (2), 552 (1992).

[10] M. Ernst, D. Walter, A. Fell, B. Lim, K. Weber. IEEE J. Photovolt., 6 (3), 624 (2016).

[11] H. Zhu, M. Wang, B. Zhang, H. Wu, Y. Sun, G. Hu, N. Dai. Jpn. J. Appl. Phys., 55 (4), 045504 (2016).

[12] Г.Е. Яковлев, Д.С. Фролов, А.В. Зубкова, В.И. Зубков, А.В. Соломонов, О.К. Стерлядкин, С.А. Сорокин. ФТП, 50 (3), 324 (2016).

[13] Г.Е. Яковлев, М.В. Дорохин, В.И. Зубков, А.Л. Дудин, А.В. Здоровейщев, Е.И. Малышева, Ю.А. Данилов, Б.Н. Звонков, А.В. Кудрин. ФТП, 52 (8), 873 (2018).

[14] D.S. Frolov, V.I. Zubkov. Semicond. Sci. Technol., 31, 125013 (2016)

[15] J.F. Ziegler, M.D. Ziegler, J.P. Biersack. Nucl. Instrum. Meth. Phys. Res. Section B: Beam Interactions with Mater. and Atoms, 268 (11), 1818 (2010).

[16] S.W. Novak, C.W. Magee, H.C. Mogul, A.J. Steckl, M. Pawlik. J. Vac. Sci. Technol. B, 10 (1), 333 (1992).

[17] X. Lu, L. Shao, J. Jin, Q. Li, I. Rusakova, Q.Y. Chen, J. Liu, W.K. Chu, P. Ling. MRS Proceedings, 610, 451 (2000).

[18] A. Gharbi, B. Remaki, A. Halimaoui, D. Bensahel, A.Souifi. J. Appl. Phys., 109(2), 023715 (2011).

Редактор Г.А. Оганесян 


\section{Technique of electrochemical \\ capacitance-voltage profiling for high doped structures with sharp doping profile}

D.S. Frolov, G.E. Yakovlev, V.I. Zubkov

St. Petersburg State Electrotechnical University

"LETI“,

197376 St. Petersburg, Russia

Abstract The specific features of electrochemical capacitancevoltage profiling technique in application for high doped structures with sharp doping profiles are described. The criteria are given and the recommendations for the choice of optimum measurement parameters are made. The necessity of increase the test signal frequency for capacitance measurements during profiling such structures is justified. The proposed technique should be used for accurate characterization of ion-implanted $p$-Si structures and $n$-GaAs epitaxial and substrate structures for $p$ HEMT devices. 